\title{
Prediction of Weather Forecasting by Using Machine Learning
}

\author{
N. Sri Lakshmi ${ }^{1}$, P. Ajimunnisa ${ }^{2}$, V. Lakshmi Prasanna ${ }^{3}$, T. YugaSravani ${ }^{4}$, and M. RaviTeja ${ }^{5}$ \\ ${ }^{1}$ Assistant Professor, Department of Computer Science and Engineering, Dhanekula Institute of Engineering and \\ Technology, Vijayawada, Andhra Pradesh, India
${ }^{2,3,4,5}$ Students, Department of Computer Science and Engineering, Dhanekula Institute of Engineering and Technology, \\ Vijayawada, Andhra Pradesh, India
}

Correspondence should be addressed to N. Sri Lakshmi; ajimunnisapathan1999@gmail.com

Copyright ( 2021 Made N. Sri Lakshmi et al. This is an open access article distributed under the Creative Commons Attribution License, which permits unrestricted use, distribution, and reproduction in any medium, provided the original work is properly cited.

\begin{abstract}
Weather forecasting has become important now a day because of varying climatic conditions around the world. Many technologies have been introduced to predict the weather whose accuracy is around $70 \%$. Weather forecasting is used in machine learning. It is a powerful technique to predict the weather with more accuracy. Weather dataset is collected and analysed and algorithms on it to predict the weather. Using a Back Propagation Neural Network the error rate becomes less and many factors that are involved to predicting the weather gives the accurate results. To compare and evaluate the performance of above model and the programming was carried out using Visual Studio as a tool.
\end{abstract}

KEYWORDS- Classification, Weather Forecasting, Weather Conditions, Rainfall Prediction, Back Propagation Neural Network.

\section{INTRODUCTOIN}

Weather forecasting is the application of science and technology to predict atmospheric conditions at specific places and times. People have tried to predict the weather officially for thousands of years since the 19th century.[1] After manual calculations, primarily based on changes in barometric pressure, current weather conditions, sky conditions or cloud cover, weather forecasts now rely on computer-based models, taking into account many atmospheric factors. Human opinion is still needed to select the optimal forecast model on which to base the forecast, including knowledge of pattern recognition technology, remote connectivity, model performance and model bias. Prediction inaccuracies are due to the turbulence characteristics of the atmosphere, the enormous computational power needed to solve the equations that describe the atmosphere, the errors associated with measuring initial conditions, and an incomplete understanding of the waiting process. Therefore, as the difference between the current time and the time when the prediction is made (prediction range) increases, the prediction accuracy decreases. Ensembles and model agreements can help narrow errors and select the most likely outcomes[3]. The end use for weather forecasts is very diverse. Weather warnings are important predictions to be used to protect life and property. Forecasts based on temperature and precipitation are important for agriculture, so they are also important for commodity market traders.
Power companies use temperature forecasts to estimate demand over the next few days. Every day many people use the weather forecast to determine what clothes to wear on a given day. Heavy rain, snow, wind chills significantly reduce outdoor activity, so forecasts can be used to plan, advance, and survive activities in the vicinity of these events[9]. Rain predictions can be used by farmers. Machine learning is a data science technique which creates a model from a training dataset. A model is basically a formula which outputs a target value based on individual weights and values for each training variable. In each record, corresponding weights (sometimes between 0 and 1) to each variable tells the model how that variable is related to the target value[5][6]. There must be sufficient amount of training data to determine the best possible weights of all the variables. When the weights are learned as accurately as possible, a model can predict the correct output or the target value given a test data record. Utilizing simple machine learning techniques allow us to be relieved from the complex and resource-hungry weather models of traditional weather stations. Such a forecasting model can be offered to the public as web services very easily[2]. Holmstrom et al. proposed a technique to forecast the maximum and minimum temperature of the next seven days, given the data of past two days[5]. They showed that both the models were outperformed by professional weather forecasting services for the prediction of up to seven days. A data mining based predictive model to identify the fluctuating patterns of weather conditions was proposed. The proposed data model uses Hidden Markov Model for prediction and $\mathrm{k}$-means clustering for extracting weather condition observations. Grover et al. studied weather prediction via a hybrid approach, which combines discriminatively trained predictive models with deep neural networks[10] that models the joint statistics of a set of weather-related variables.

\section{EXISTING SYSTEM}

Ms. Ashwini Mandale et al developed on Data mining techniques it used the algorithm Decision tree Algorithms for meteorological to forecast weather[1]. Ankita Joshi et al proposed a data mining techniques of decision tree algorithm. They found 63\% accuracy in variation of rainfall for our proposed model. There are several limitations in better implementation of weather forecasting in data mining techniques. They used only small 
limited areas for weather forecasting. Accurate weather prediction is a difficult task due to dynamic change of atmosphere[7].

\section{PROPOSED SYSTEM}

Weather forecasting is used in machine learning. It is a powerful technique to predict the weather with more accuracy. Weather dataset is collected and analysed and algorithms on it to predict the weather. Using a Back Propagation Neural Network model the error rate becomes less and many factors that are involved to predicting the weather gives the accurate results. To compare and evaluate the performance of above model and the programming was carried out using MATLAB as a tool. Through our proposed system we would like to improve the overall performance by using the regression and classification neural network architectures through frameworks such as Tensorflow and keras.



Fig. 1: Back Propagation working process

- We first initialized some random value to ' $\mathrm{W}$ ' and propagated forward.

- Then, we noticed that there is some error. To reduce that error, we propagated backwards and increased the value of ' $W$ '.

- After that, also we noticed that the error has increased. We came to know that, we can't increase the ' $W$ ' value.

- So, we again propagated backwards and we decreased 'W' value.

- Now, we noticed that the error has reduced.

\section{A. Functional Requirements}

The following are the Functional requirements of our system.

Data should be reliable for prediction. Based on the data temperature is given to the user.

\section{B. Non- Functional Requirements}

In software engineering and requirements engineering a non-functional requirement is a requirement that specifies criteria that can be used to judge the operation of a system rather than specific behaviours.

The project non-functional requirements include the following:

Basic knowledge on the traditional weather forecasting system.

- Availability

- Flexibility

- Scalability

- Usability

- Performance

\begin{tabular}{|c|c|c|c|}
\hline \multicolumn{4}{|c|}{ IV. RESULTS } \\
\hline \multicolumn{4}{|l|}{ CLICK TO PREDICT } \\
\hline meandewptm & 11.8 & 11.88 & 11.85 \\
\hline meanpressure & 1009.45 & 1009.41 & 1009.41 \\
\hline maxhumidity & 67.62 & 67.21 & 67.05 \\
\hline minhumidity & 22.84 & 22.70 & 22.58 \\
\hline maxdewptm & 16.10 & 16.11 & 16.10 \\
\hline mindewptm & 7.25 & 7.29 & 7.45 \\
\hline maxpressurem & 1012.22 & 1012.19 & 1012.18 \\
\hline minpressurem & 1005.23 & 1005.18 & 1005.20 \\
\hline precipm & 1.14 & 1.33 & 1.19 \\
\hline \multicolumn{4}{|c|}{$\begin{array}{l}\text { Predicted temperature:24.557928degrees } \\
\text { Rainy }\end{array}$} \\
\hline
\end{tabular}

Fig. 2: Algorithm Predicting the Weather

We are taking the inputs as last 3 days parameters like meandewpoint,meanpressure,maxhumidity,minhumidity,ma xdewpoint,mindewpoint,minpressure,maxpressure,precipita tion.By taking these parameters regression technique will perform the operations by using the libraries like numpy,pandas. Running the code in Microsoft Visual Studio Code it will displays the predicted temperature.

\section{CONFLICTS OF INTEREST}

The authors declare that they have no conflicts of interest.

\section{CONCLUSION}

The proposed methodology aims at providing an efficient weather forecasting framework for predicting and monitoring the weather attribute datasets to predict. In past the parameters of weather were recorded only for the present time only. The future work will explore a working model of selection that can be classifying the framework for continuous monitoring the climatic attributes.

\section{REFERENCES}

[1] Ms. Ashwini Mandale, "Weather Forecast Prediction: A Data Mining Application", International Journal of Engineering Research and General Science Volume 3, Issue 2, MarchApril, 2015, ISSN 2091-2730.

[2] Imran Maqsood, Muhammad Riaz Khan, and Ajith Abraham, "An ensemble of neural network for weather forecasting", 
Neural Comput\&Applic (2004) 13: 112-122

[3] Amanpreet Kaur, J K Sharma, and Sunil Agrawal, "Artificial neural networks in forecasting maximum and minimum relative humidity". International Journal of Computer Science and Network Security, 11(5):197-199, May 2011

[4] Sawaitul, D. Sanjay, K. P. Wagh and P. N. Chatur, "Classification and prediction of future weather by using back propagation algorithm-an approach", International Journal of Emerging Technology and Advanced Engineering, Vol. 2, No. 1, pp. 110-113, 2012.

[5] Ankita Joshi, BhagyashriKamble, Vaibhavi Joshi, KomalKajale, NutanDhange, "Weather Forecasting And Climate Changing Using Data Mining Application", International Journal Of Advanced Research In Computer And Communication Engineering,Vol. 4, Issue 3, March 2015.

[6] M. Viswambari, Dr. R. AnbuSelvi, "Data Mining Techniques To Predict Weather: A Survey", ISSN 2348 - 7968, IJISETInternational Journal Of Innovative Science, Engineering \& Technology, Vol. 1 Issue 4, June 2014.

[7] Divya Chauhan, Jawahar Thakur, "Data Mining Techniques for Weather Prediction: A Review", International Journal On Recent and Innovation Trends In Computing And Communication ISSN: 23218169 Volume: 2 Issue: 8, 2014.

[8] Fairbridge R. W., 2007, "Climate" Microsoft® Student 2008 [DVD], Redmond, WA: Microsoft Corporation, 2007.

[9] Han, J., Micheline K., 2007, Data Mining: Concepts and Techniques, San Fransisco, CA: Morgan Kaufmann publishers.

[10] Nikhil Sethi, Dr.KanwalGarg,"Exploiting Data Mining Technique For Rainfall Prediction", Nikhil Sethi Et Al, / (IJCSIT) International Journal Of Computer Science And Information Technologies, Vol. 5 (3), 2014, 3982-3984.

\section{ABOUT THE AUTHORS}

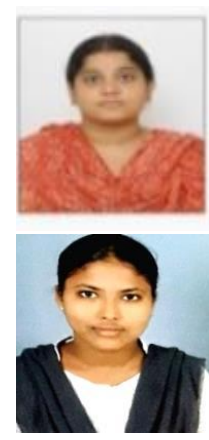

Mrs. N. Sri Lakshmi, Assistant Professor, Department of Computer Science and Engineering, Dhanekula Institute of Engineering and Technology. Vijayawada, Andhra Pradesh, India

P. Ajimunnisa, Student of B.Tech Final Year, Department of Computer Science and Engineering, Dhanekula Institute of Engineering and Technology, Vijayawada, Andhra Pradesh, India

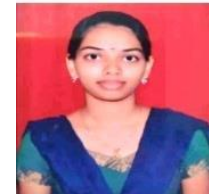

V. Lakshmi Prasanna, Student of B.Tech Final Year, Department of Computer Science and Engineering, Dhanekula Institute of Engineering and Technology, Vijayawada, Andhra Pradesh, India

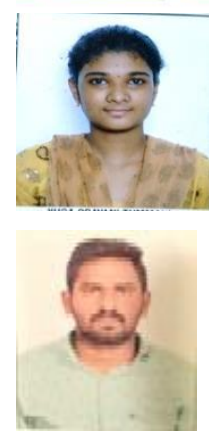

T. YugaSravani, Student of B.Tech Final Year, Department of Computer Science and Engineering, Dhanekula Institute of Engineering and Technology, Vijayawada, Andhra Pradesh, India

M. Ravi Teja, Student of B.Tech Final Year, Department of Computer Science and Engineering, Dhanekula Institute of Engineering and Technology, Vijayawada, Andhra Pradesh, India 